\begin{tabular}{|l|l|l|l|l|}
\hline Jurnal Penelitian \& PKM & Juli 2017 & Vol 4, No: 2 & Hal: $129-389$ & ISSN \\
\hline
\end{tabular}

\title{
PENTINGNYA MEMAHAMI PERAN DAN FUNGSI SERTA KODE ETIK SUPERVISI PEKERJA SOSIAL DALAM PROFESI PEKERJA SOSIAL DI INDONESIA
}

\author{
OLEH: \\ FADILLA RAMA WIDAPRATAMA ${ }^{1}$, SANTOSO TRI RAHARJO²

\begin{abstract}
1Mahasiswa Program Studi Kesejahteraan Sosial (170310140019), Fakultas Ilmu Sosial dan Ilmu Politik, Universitas Padjadajaran

2PPusat Studi Kewirausahaan Sosial, CSR, dan Pengembangan Masyarakat, Fakultas Ilmu Sosial dan Ilmu Politik, Universitas Padjadajaran
\end{abstract}

Email:

adillaramawidapratama35@gmail.com, santoso.tri.raharjo@unpad.ac.id

\begin{abstract}
ABSTRAK
Etika adalah suatu komponen penting yang harus dijaga dengan baik oleh seluruh manusia, khususnya bagi seseorang yang bergerak dalam bidang keprofesionalan dan pekerjaan sosial lah salah satunya. Kode etik merupakan salah satu pedoman bagi para pekerja sosial dalam menjalankan langkah keprofesionalan dalam praktiknya. Maka dari itu, dalam menjalankan profesinya kode etik memiliki peran vital dalam peran kerja antara pekerja sosial dengan klien, maupun antara pekerja sosial dengan supervisor pekerja sosial. Lalu, adakah perbedaan di dalamnya antara kode etik pekerja sosial dengan kode etik supervisi pekerja sosial? Banyak orang menilai bahwa dengan memegang teguh nilai etika bagi pekerja sosial sudahlah lebih dari cukup bagi pekerja sosial dalam menjalankan tugas profesionalnya terhadap klien. Lantas, mengapa harus ada supervisor pekerja sosial? Adakah nilai dan tanggung jawab lebih atasnya terhadap peran dan fungsi supervisi pekerja sosial tersebut? Dalam artikel ini, penulis akan menjabarkan perihal pentingnya memahami dan mengetahui kode etik (nilai etika) yang harus dipahami dan diketahui. Sehingga, kedepannya khalayak yang khususnya mahasiswa prodi Kesejahteraan Sosial dapat memahami apa yang dimaksud dengan supervisi pekerja sosial dalam praktik pekerjaan sosial, mengapa diharuskannya terdapat supervisi pekerjaan sosial dalam praktik pekerja sosial, dan paling utama mengenai nilai etika yang dipegang oleh para supervisor pekerja sosial.
\end{abstract}

\begin{abstract}
Ethics is an important component that must be maintained by all human beings, especially for someone who is engaged in professionalism and social work is one of them. The code of conduct is one of the guidelines for social workers in carrying out professionalism in practice. Therefore, in carrying out its profession ethical code has a vital role in the role of work between social workers with clients, as well as between social. Then, is there a difference between the social worker's code of conduct and the social worker supervision code of ethics? Many people judge that by upholding the ethical value of social workers it is more than enough for social workers to carry out their professional duties to clients. So why should there be a social worker supervisor? Is there any value and more responsibility for the role and function of the supervision of the social worker? In this article, the author will describe the importance of understanding and knowing the ethical code
\end{abstract}


(ethical values) that must be understood and known. Thus, in the future, audiences who are especially Social Welfare Program students can understand what is meant by the supervision of social workers in social work practices, why they are required to supervise social work in social worker practice, and most importantly the ethical values held by social worker supervisors.

Kata kunci : Supervisi, Etika, Pekerja Sosial.

\section{PENDAHULUAN}

Pekerja Sosial merupakan salah satu dari sekian banyak profesi yang sangat penting di dunia. Pengetahuan dan keterampilan khusus yang dimiliki para Pekerja Sosial menempatkan pada posisi strategis dalam berbagai bidang. Terbukti bahwa profesi Pekerja Sosial merupakan salah satu dari delapan karir terbaik (Wall Street Journal 2006 dalam Ritter, 2009 ). Kemampuan seorang Pekerja Sosial tentu tidak terlepas dari nilai, etik, kualitas, pengetahuan dan keterampilan praktik yang baik.

Menurut Martin (1993), etika didefinisikan sebagai "the discpline which can act as the performance index or reference for our control system". Dengan demikian, etika akan memberikan semacam batasan maupun standar yang akan mengatur pergaulan manusia di dalam kelompok sosialnya. Dalam pengertiannya yang scara khusus dikaitkan dengan seni pergaulan manusia, etika ini kemudian dirupakan dalam bentuk aturan (code) tertulis yang secara sistematik sengaja dibuat berdasarkan prinsipprinsip moral yang ada dan pada saat yang dibutuhkan akan bisa difungsikan sebagai alat untuk menghakimi segala macam tindakan yang secara logikarasional umum (common sense) dinilai menyimpang dari kode etik. Dengan demikian etika adalah refleksi dari apa yang disebut dengan "self control", karena segala sesuatunya dibuat dan diterapkan dari dan untuk kepenringan kelompok sosial (profesi) itu sendiri. ${ }^{7}$

7

http://eprints.undip.ac.id/4907/1/Etika_Profesi.pdf didownload dan diakses pada $21 \mathrm{Mei}, 18.15$ WIB
Kode etik dalam praktik pekerja sosial adalah pedoman perilaku bagi anggota Ikatan Pekerja Sosial Profesional Indonesia (IPSPI) dan merupakan landasan untuk memutuskan persoalan-persoalan etika bila perilaku pekerja sosial profesioanal dinilai menyimpang dari standar perilaku etis dalam melaksanakan hubunganhubungan profesionalnya dengan kelayakan, kolega, profesi lain dan dengan masyarakat. Kode etik ini didasarkan pada nilai-nilai fundamental pekerja social yakni penghargaan terhadap martabat dan harga diri setiap orang, serta hakhak dan tanggung jawab social.

Kode etik pekerja sosial tidak sertamerta perangkat yang menentukan semua perilaku pekerja sosial professional dalam semua kompleksitas kehidupan. Kode etik bagi para pekerja sosial lebih berisikan tentang prinsipprinsip umum untuk membimbing perilaku dan menilai perilaku secara bijaksana dalam berbagai situasi yang mengandung implikasi etis.

Kode etik ini tidak dimaksudkan sebagai alat untuk menghilangkan/mencabut kesempatan atau kebebasan pekerja social professional yang melakukan praktek dengan integritas profesional yang tinggi. Perilaku pekerja social professional bukan berasal dari dekrit/ maklumat, tetapi komitmen pekerja social professional secara individual. Kode etik ini dibuat untuk menegaskan kemauan dan semangat pekerja social professional agar bertindak etis dalam seluruh perbuatan mereka sebagai pekerja social professional. ${ }^{8}$

8 https://www.slideshare.net/marlinrospita/kode-

etik-pekerja-sosial diakses pada 21 Mei, 2017. 
Dalam kegiatan profesionalnya, pekerja sosial membutuhkan yang namanya pendamping dalam upaya intervensi menyelesaikan masalah yang dialami oleh klien. Maka dari itu, seorang pekerja sosial membutuhkan yang namanya supervisi. Supervisi pun memiliki tugas tersendiri dalam kegiatan profesionalnya, yaitu tugas normatif: "tanggung jawab bersama dari pengawas dan (konselor) untuk memantau standar dan praktek etika konselor", tugas formatif: "tanggung jawab bersama untuk pengembangan konselor dalam keterampilan, pengetahuan dan pemahaman, tugas restoratif: "penyediaan ruang, atau kesempatan untuk mencari peluang yang lebih baik di tempat lain, caranya memanfaatkan peluang-peluang curah rasa dan pengisian energi, cita-cita dan kreativitas". Dalam peran dan tugas yang dilakukan supervisi tersebut, tidak sertamerta bahwa supervisi lah komponen bebas yang terkesan "paling atas" bagi pekerja sosial. Supevisi pun sama halnya dengan pekerja sosial yang memiliki kode etik yang menjadi pedoman bagi dirinya dalam menjalankan profesinya sebagai supervisi pekerja sosial. (Inskipp dan Proctor,1993, p.6, dalam kuliah Supervisi Pekerja Sosial).

Sudah saatnya kahalayak tahu perihal kegiatan supervisi dalam praktik pekerja sosial, termasuk nilai, peran, tugas bahkan kode etik yang ada di dalamnya. Supervisi merupakan komponen penting dalam praktik pekerja sosial. Maka dari itu, perlu lah khalayak terutama para calon pekerja sosial mengetahui mengenai nilai, peran, fungsi, tujuan dan terutama kode etik yang dipegang teguh pleh para supervisi pekerja sosial dalam kegiatan profesionalnya.

\section{PEMBAHASAN}

Pentingnya peranan nilai dan etika dalam pekerjaan sosial menjadikan keduanya sebagai salah satu fondasi pengetahuan mendasar yang harus dimiliki oleh pekerja sosial dan supervisor pekerja sosial. Tidak mungkin aktivitas pertolongan dapat menjadi suatu profesi spesialis tanpa adanya pengetahuan bahwa menolong orang adalah nilai yang baik. Ketika menolong orang dianggap sebagai suatu nilai yang baik, maka secara etis perilaku digerakkan untuk menolong seseorang yang membutuhkan karena itu adalah kebenaran. Keyakinan-keyakinan tentang sesuatu yang baik menuntut pekerja sosial untuk melakukannya karena perbuatan tersebut adalah benar. Sebaliknya, keyakinan-keyakinan mengenai sesuatu yang buruk mencegah pekerja sosial sehingga menghindarinya karena perbuatan tersebut adalah salah. Nilai dan etika pada akhirnya menjadi kunci petunjuk terhadap perbuatan baikburuk atau benar-salah. Keyakinan tentang nilai yang benar juga berperan sebagai petunjuk bagi pekerja sosial untuk memutuskan suatu perkara ketika terjadi dilema etis dalam melakukan intervensi sosial (dalam Huda, 2009:141-142).

Seorang supervisor haruslah bekerja sesuai dengan protokoler dan prosedur yang menyangkut kode etik supervisor yang tentunya tanpa menghilangkan atau melupakan nilai etika pekerja sosial itu sendiri. Prinsip etiknya adalah supervisor pekerja sosial harus mengutamakan tujuan untuk membantu pekerja sosial yang membutuhkan dan memusatkan pada permasalahan sosial yang terdapat pada diri klien pekerja sosial tersebut. Prinsip pelayanan diletakkan diatas kepentingan pribadi maupun kepentingan golongan. Melayani dan membimbing dalam penyelesaian masalah yang dialami klien kepada pekerja sosial baik individu dan kelompok merupakan kewajiban yang tercatat dalam tugas pokok dan fungsi dari supervisor pekerja sosial yang harus diutamakan. Tanpa prinsip pelayanan, seorang supervisor

Pukul

18.25 WIB. 
pekerjaan sosial tidak memiliki aktivitas profesional, terutama dalam hal pengawasan. Pengawasan adalah kegiatan yang sangat dipengaruhi oleh infrastruktur dan hubungan variabel. Dengan kata lain, kinerja akan sebagus perhatian yang telah dibayarkan kepada variabel-variabel yang tampaknya asing '(Bernard 2005, p.9). Tiga kualitas yang mendasari relasi supervision yang baik: keaslian, saling hormat dan berfikir positif, serta saling investasi atau keterbukaan untuk saling belajar. Telah dipatikan bahwa adanya kode nilai etika tersendiri yang harus dipegang teguh oleh seorang supervisor ketika bekerja dengan pekerja sosial yang sedang menangani kliennya, antara lain meliputi :

\section{Harkat dan Martabat Seseorang}

Prinsip etik pertama supervisor pekerja sosial adalah menghormati harkat dan martabat seorang pekerja sosial yang tersupervisi. Pekerjaan sosial merupakan profesi yang melibatkan diri langsung baik dalam setting individu, keluarga, kelompok maupun masyarakat. Oleh sebab itu, setting keterlibatan langsung ini menuntut dari para supervisor pekerja sosial untuk memiliki modal nilai yang menghargai orang lain dalam melakukan interaksi sosial, terutama bila sedang dalam keadaan berhadapan oleh pekerja sosial yang tersupervisi olehnya. Di sinilah peran yang agak memerlukan emosional, karena supervisor pekerja sosial tersebut semampu mungkin membantu pekerja sosial tersebut tanpa harus membuat pekerja sosial tersebut merasa gagal dalam menangani kliennya. Di sinilah skill tersendiri yang dimiliki oleh supervisor pekerja sosial yang tak hanya mampu berempati dalam menempatkan dirinya menjadi klien dari sorang pekerja sosial, melainkan berempati menajadi seorang pekerja sosial yang sedang berhadapan dengan masalah klien dengan tetap profesional menempatkan dirinya sebagai seorang supervisor.

\section{Mementingkan Hubungan Kemanusiaan}

Mementingkan hubungan kemanusiaan merupakan prinsip etik dari pekerja sosial beserta supervisor yang mengakui dan mengutamakan hubungan kemanusiaan. Hubungan kemanusiaan (human relationship) adalah unsur yang sangat penting di dalam proses perubahan sosial. Maka dari itu, menjunjung tinggi hubunga kemanusiaan dan kemasyarakatan harus dilakukan untuk mendukung perubahan sosial agar berjalan secara positif. Hubunga kemanusiaan adalah bagian dari proses pertolongan. Baik antara pekerja sosial dengan klien, maupun antara supervisor dengan pekerja sosial.

\section{Integritas}

Intergritas merupakan salah satu prinsip nilai etik, yang pada intinya supervisor pekerja sosial harus mempunyai perilaku yang dapat dipercaya. Dalam batas tertentu, profesi pekerja sosial adalah seperti dokter, 'mengobati' dan 'menyembuhkan' individu, keluarga, kelompok atau masyarakat yang sedang sakit. Tanpa adanya perilaku yang dapat dipercaya, supervisor pekerja sosial tidak dapat menjalankan profesi tersebut dengan baik. Integritas setidaknya ditunjukkan dengan konsistensi supervisor pekerja sosial dengan pekerja sosial dengan misi profesional, nilai, dan prinsip etika, serta standar etika dalam aktivitas pertolongan kepada pekerja sosial yang dilakukannya.

\section{Kompetensi}

Prinsip etik dari nilai ini adalah supervisor pekerja sosial harus mempraktikkan keahlian profesionalismenya dalam proses pertolongan dan bimbingan kepada pekerja sosial yang tersupervisi olehnya. Dalam hal ini pengetahuan dan skill supersivor pekerja sosial harus terpaut diatas pengetahuan dan skill pekerja sosial yang tersupervisi olehnya untuk menunjang kompetensi dari praktik pekerja sosial. Tanpa adanya kompetensi tersebut menjadikan supervisor pekerja sosial tidak dapat profesional dan mencapai tujuannya dengan baik. Sehingga 
adanya pengetahuan dan keahlian yang memadai juga menjadi dasar kepemilikan yang sangat penting dalam profesi menjadi supervisor pekerjaan sosial.

Kompetensi dan pengetahuan sebagai praktisi, kompetensi dan terlatih sebagai supervisor , kemampuan untuk menghadapi secara suportif, keterbukaan untuk umpan balik dan kemampuan untuk memonitor diri, kemampuan untuk memberikan dukungan dan bertahan untuk berbagai situasi dan emosi, kemampuan untuk mengelola kewenangan dan otoritas, mereka menerima dan dihargai pengawasan mereka sendiri (Davys 2005b, p.16), merupakan hal-hal penting yang memiliki peran vital atas keberhasilan pekerja sosial atas penyelesaian masalah yang klien miliki.

\section{PENUTUP}

\section{SIMPULAN}

Pentingnya peranan nilai dan etika dalam pekerjaan sosial menjadikan keduanya sebagai salah satu fondasi pengetahuan mendasar yang harus dimiliki oleh pekerja sosial dan supervisor pekerja sosial. Tidak mungkin aktivitas pertolongan dapat menjadi suatu profesi spesialis tanpa adanya pengetahuan bahwa menolong orang adalah nilai yang baik. Ketika menolong orang dianggap sebagai suatu nilai yang baik, maka secara etis perilaku digerakkan untuk menolong seseorang yang membutuhkan karena itu adalah kebenaran. Keyakinan-keyakinan tentang sesuatu yang baik menuntut pekerja sosial untuk melakukannya karena perbuatan tersebut adalah benar. Sebaliknya, keyakinan-keyakinan mengenai sesuatu yang buruk mencegah pekerja sosial sehingga menghindarinya karena perbuatan tersebut adalah salah. Nilai dan etika pada akhirnya menjadi kunci petunjuk terhadap perbuatan baikburuk atau benar-salah. Keyakinan tentang nilai yang benar juga berperan sebagai petunjuk bagi pekerja sosial untuk memutuskan suatu perkara ketika terjadi dilema etis dalam melakukan intervensi sosial (dalam Huda, 2009:141-142).

Pada intinya, supervisi pekerja sosial memiliki peran yang sangat amat penting dalam praktik pekerja sosial, terutama berkaitan dengan langkah pengerjaan penyelesaian masalah antara pekerja sosial yang tersupervisi kepada kliennya. Dengan mengetahui dan memahami kode etik supervisor pada praktik pekerja sosial, mahasiswa Program Studi Kesejahteraan Sosial FISIP Unpad sadar akan pentingnya supervisor bagi pekerja sosial yang notabene merekalah komponen yang nantinya akan menjadi salah satu bagian yang tersupervisi dalam kegiatan profesionalnya.

\section{SARAN}

Penulis cukup mendapatkan kendala dalam menyusun atikel ini, terutama perihal kajian literatur sebagai referensi penulisan artikel. Ditambah lagi, supervisi pekerja sosial merupakan salah satu mata kuliah abru yang terdapat pada Program Studi Kesejahteraan Sosial FISIP Unpad. Hal tersebut mengakibatkan belum adanya contoh seperti apa mata kuliah Supervisi Pekerja Sosial ini baik dalam penugasan dan materi. Dapat dibilang tahun ini merupakan tahun percobaan atas mata kuliah Supervisi Pekerja Sosial yang diterapkan di Pogram Studi Kesejahteraan Sosial FISIP Unpad.

Atas kendala dari penulis yang sudah dibahas di atas menyimpulkan beberapa saran, diantaranya dibutuhkannya literatur mengenai supervisi pekerja sosial baik berbahasa Indonesia maupun berbahasa Inggris. Hal tersebut sangat membantu bagi para mahasiswa khususnya bagi mereka yang menjadi calon pekerja sosial dan tertarik dalam aspek supervisi. Begitu perlunya sounding perihal supervisi pekerja sosial sebagai mata kuliah yang menarik bagi para mahasiswa untuk mengetahui bahwa ada komponen penting di dalam keberhasilan pekerja sosial dalam membantu menyelesaikan permasalahan yang terdapat pada klien, yang tak lain berkat adanya supervisor dalam praktik pekerja sosial. 


\begin{tabular}{|c|c|c|c|c|}
\hline Jurnal Penelitian \& PKM & Juli 2017 & Vol 4, No: 2 & Hal: $129-389$ & $\begin{array}{c}\text { ISSN } \\
\text { 2442-448X (p), 2581-1126 (e) }\end{array}$ \\
\hline
\end{tabular}

\section{DAFTAR PUSTAKA}

Alston, M. \& Bowles, W. (2003) 2nd Edition. Research for Social Workers. South Wales: Allen and Unwin Publishers

BESSIE KENT, 1969, SOCIAL WORK SUPERVISION IN PRACTICE, Pergamon Press Ltd.,

Creswell, J.W. (2007) 2nd Edition. Qualitative Enquiry and Research Design: Choosing Among

http://eprints.undip.ac.id/4907/1/Etika_Profesi .pdf didownload dan diakses pada 21 Mei, 18.15 WIB

https://www.slideshare.net/marlinrospita/kode -etik-pekerja-sosial diakses pada 21 Mei, $2017 . \quad$ Pukul 18.25 WIB.

http://www.socialworktoday.com/archive/july aug2007p34.shtml diakses pada 22 Mei, $2017 . \quad$ Pukul 9.20 WIB.

Davys, Allyson, 1952. Best practice in professional supervision : a guide for the helping professions / Allyson Davys and Liz Beddoe.

NASW, 2013. Best Practice Standards Social Work Supervision. National Association of Social Workers.

Jeanne Marie Hughes, BA (Early Childhood Studies), MSW, The Role of Supervision in Social Work: A critical analysis. Critical Social Thinking: Policy and Practice, Vol. 2, 2010.

O’Donovan, D. (2000) Supervision and Practitioners in Social Contexts. Dublin: National Youth Federation.

Page, S. \& Wosket, V. (1994) Supervising the Counsellor: A Cynical Model. London: Routledge.
Raharjo, ST.2015. Manajemen Relawan pada Organisasi Pelayanan Sosial. Unpad Press.

2015. Keterampilan Pekerjaan Sosial, Dasar-dasar. Unpad Press 2015. Dasar Pengetahuan Pekerjaan Sosia. Unpad-Press. 